\title{
Platelet-like catalyst design for high yield production of multi-walled carbon nanotubes by catalytic chemical vapour deposition
}

J. David Núñez ${ }^{1,2}$, Wolfgang K. Maser ${ }^{1}$, M. Carmen Mayoral ${ }^{1}$, José M. Andrés ${ }^{1}$, Ana M. Benito ${ }^{* 1}$

${ }^{1}$ Instituto de Carboquímica (CSIC), C/Miguel Luesma Castán 4, E-50018 Zaragoza. Spain.

${ }^{2}$ Centro de Estudios Avanzados de Cuba. CEAC. La Habana. Cuba. Carretera San Antonio, km 1-1/2, Puentes Grandes. Ciudad de la Habana. Cuba.

\begin{abstract}
We investigated the effect of catalyst design on the synthesis of multi-walled carbon nanotubes (MWCNTs) by chemical vapour deposition (CVD). A set of highly active supported sol-gel $\mathrm{Co}-\mathrm{Mo} / \mathrm{MgO}$ and $\mathrm{Ni}-\mathrm{Mo} / \mathrm{MgO}$ catalysts was prepared systematically modifying the calcination temperature. First, the evolution of catalysts' crystallographic phases and their morphology were studied by X-ray diffraction (XRD), Raman spectroscopy, scanning electron (SEM) and transmission electron (TEM) microscopy. Second, the catalysts were used for the CVD growth of MWCNTs. The resulting materials were analysed by SEM and TEM, Raman and XRD to establish a relation between catalyst design and MWCNT yield. We show that our catalyst synthesis route leads to the formation of laminar non-porous catalyst systems, which at a calcination temperature of $800^{\circ} \mathrm{C}$ stabilise in a crystallographic phase of $\mathrm{Me}_{\mathrm{x}} \mathrm{Mg}_{1-\mathrm{x}} \mathrm{MoO}_{4}(\mathrm{Me}=\mathrm{Co}$ or Ni). We give evidence that increased MWCNT yields of more than $3000 \mathrm{wt} \%$ with
\end{abstract}

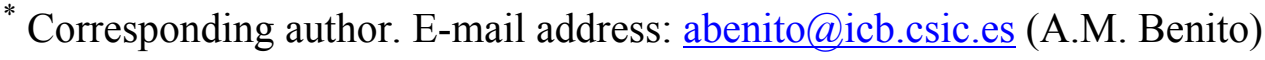


respect to the catalysts are directly related to the aforementioned crystallographic phase. Finally, we propose a growth model based on the continuous exfoliation of platelet-like catalyst systems. This consistently explains the high catalytic activity towards MWCNT production using a non-porous catalyst. Our findings provide important insights for catalyst design strategies towards large-scale MWCNT production.

\section{Introduction}

The exceptional mechanical, thermal, electronic and chemical properties of carbon nanotubes (CNTs) [1] are the origin of enormous research activities in various fields of science and technology such as electronics, biology, materials science and energy conversion storage/conversion [2]. Progress for large-scale applications strongly depends on the availability of CNTs at competitive prices. Many efforts have been made in the last decade to develop low cost large-scale synthesis processes. Most promising are chemical vapour deposition (CVD) based methods, including fluidized bed techniques [3,4]. On one hand, they offer opportunities for a continuous and automatised production line. On the other hand, a broad set of process variables (temperature, carbon-precursor, catalyst, promoters, fluid-dynamics, etc.) ensures a high versatility to tune both CNTs characteristics and yield. However, understanding the role

of the various process parameters is still a major issue when it comes to gain full control on CNT growth and to develop an effective large-scale production, which is of uppermost interest for further progress towards CNT-based products.

Among all the process parameters, catalysts are of special relevance for the formation of CNTs. Catalyst type (typically $3 \mathrm{~d}$ metals), size (optimally in the range of a few $\mathrm{nm}$ ) and activity largely define CNTs structural characteristics and the production yields [5-7]. The use of porous supporting matrices such as silica, alumina, zeolites, etc. is a highly 
valuable way to achieve a homogeneous distribution of nanometer sized catalytic metal particles and ensure a high catalytic activity during the CVD process [8-10]. Synthesis strategies for these types of supported catalyst systems include impregnation, coprecipitation, combustion, and sol-gel methods [11-13]. The latter is based on low cost up-scalable chemical synthesis routes which can be adapted, e.g. by the addition of promoters, to design highly effective catalysts applicable as powders or even as coated films for tailored CNT growth [14-16]. However, very little information is available in what concerns the direct influence of catalyst preparation conditions on the growth of CNTs in high yields.

In this work we designed highly active $\mathrm{Co}-\mathrm{Mo} / \mathrm{MgO}$ and $\mathrm{Ni}-\mathrm{Mo} / \mathrm{MgO}$ sol-gel catalyst systems for high yield CVD production of MWCNTs. The effect of calcination temperatures on the structure and morphology of the catalyst was studied in detail and its direct impact on the influence of MWCNT yield was evaluated. We show that our synthesis strategy leads to layered non-porous catalyst systems in which a crystallographic phase of $\mathrm{Me}_{\mathrm{x}} \mathrm{Mg}_{1-\mathrm{x}} \mathrm{MoO}_{4}(\mathrm{Me}=\mathrm{Co}, \mathrm{Ni})$, stabilized at a calcination temperature of $800{ }^{\circ} \mathrm{C}$, is responsible for achieving MWCNT yields of more than 3000 $w t \%$ with respect to the initial catalyst. Finally we present a growth model, which is based on the continuous exfoliation of the layered catalyst systems. This coherently explains the high activity of the developed non-porous catalysts and the high-yield production of MWCNTs organised in bundles grown from catalyst fragments whose sizes are related to the bundle diameters.

\section{Experimental section}

\subsection{Catalyst synthesis and CVD reaction conditions}


Catalysts were synthesized by the sol-gel method using $\mathrm{MgO}$ as catalyst support according to a procedure reported elsewhere [17]. In this way, two types of catalyst systems were prepared Co-Mo, and Ni-Mo with identical chemical compositions except for the active metal used which was Co, or Ni respectively.

\section{Table 1 Catalyst metal loadings (at \%)}

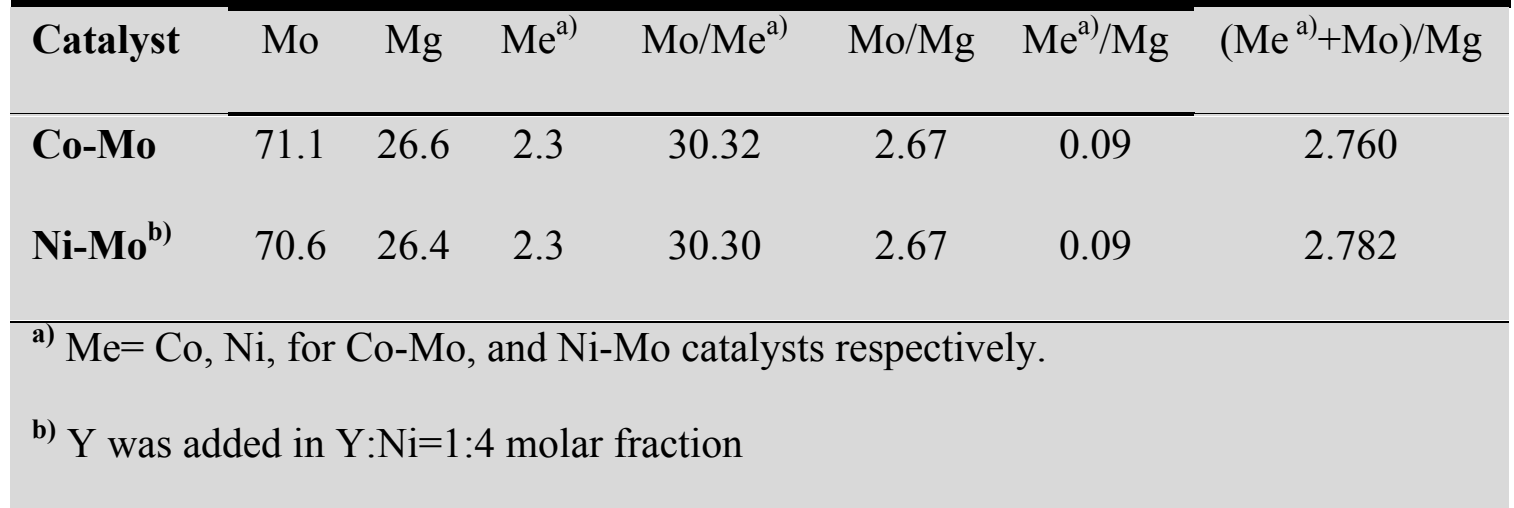

Basically, metal nitrates precursors $\mathrm{Me}\left(\mathrm{NO}_{3}\right)_{2}(\mathrm{Me}=\mathrm{Co}, \mathrm{Ni})$, and $\mathrm{Mg}\left(\mathrm{NO}_{3}\right)_{2}$ are mixed in a citric acid solution, and stirred until complete dilution is achieved. The solution is dried at $120^{\circ} \mathrm{C}$ into a foamy paste, which is mixed with molybdenum before performing the subsequent calcinations step. Catalyst metal loadings are shown in table 1 . In the case of Ni-catalyst systems, yttrium (in the form of nitrate) was added in a Ni:Y molar ratio of 4:1 to enhance MWCNT yield, according to our former observations [18].

To study the influence of the catalyst preparation temperature on the synthesis of carbon nanotubes, the calcination process was performed at three selected temperatures, i.e. at $700^{\circ} \mathrm{C}, 750^{\circ} \mathrm{C}$, and $800^{\circ} \mathrm{C}$. In this way, 6 different catalyst samples were obtained and characterized. Subsequently, they were used under identical conditions in a CVD process designed for MWCNT production as described previously [17]. In brief, a flow composed by methane $\left(1000 \mathrm{~cm}^{3} / \mathrm{min}\right)$ and hydrogen $(100: 3 \mathrm{v} / \mathrm{v})$ passes through a 
quartz reactor (30 $\mathrm{mm}$ of inner diameter) placed inside a horizontal furnace. At a reaction temperature of $1000{ }^{\circ} \mathrm{C}$, methane decomposes in the presence of the catalyst (50 mg) deposited as fine powder on a ceramic boat. After a reaction time of 30 minutes and the subsequent cooling period, MWCNT were collected from the ceramic boat, weighted and characterised.

Both catalysts and produced MWCNT materials were characterised in detail by different techniques. Structural and morphological characteristics were studied by transmission electron microscopy (TEM) on a JEOL JEM-2000FX II as well as by scanning electron microscopy (SEM) on a HITACHI S3400N. SEM-EDX mapping was applied to evaluate the homogeneity of metal deposition on the supported catalysts. Physical-chemical changes of the catalyst systems taking place during the calcinations step were studied using a combined differential scanning calorimetry-thermogravimetric analysis (DSC-TGA) in a SDT TA Instruments Q600. Samples were heated with a constant ramp of $20^{\circ} \mathrm{C} / \mathrm{min}$ until $900{ }^{\circ} \mathrm{C}$ under a flow of $40 \mathrm{ml} / \mathrm{min}$ of argon and 50 $\mathrm{ml} / \mathrm{min}$ of oxygen. X-ray powder diffraction measurements (XRD) on a Bruker D8 Advance Diffractometer were performed to identify the main crystallographic phases of the catalysts as well as to probe the crystalline structure of the produced MWCNT samples. Diffractograms were obtained using a $\mathrm{Cu} \mathrm{K}_{\alpha}$ radiation $(\lambda=0.1542 \mathrm{~nm})$ in a $2 \theta$ range from $3^{\circ}$ to $80^{\circ}$, with $0.05^{\circ}$ step size and $3 \mathrm{~s}$ of acquisition time. The qualitative identification of crystalline phases of the catalysts was carried out using the EVAV 8.0 program of the DIFFRAC plus package of Bruker AXS. Raman spectroscopy of the catalysts was employed to elucidate the chemical coordination of the different species in the catalyst systems thus completing structural information obtained by XRD. Raman spectroscopy also was used to elucidate the characteristics of the produced MWCNT materials. Corresponding measurements were carried out using a Horiba Jobin Yvon 
HR800 UV spectrometer at an excitation wavelength of $532 \mathrm{~nm}$. Spectra for catalysts and MWCNT materials were accumulated in 5 runs using an acquisition time of $45 \mathrm{~s}$ per run. The BET specific surface area of the catalysts was calculated from the nitrogen adsorption data acquired from nitrogen adsorption isotherms at liquid nitrogen temperature on a Micromeritics ASAP 2010 adsorption apparatus.

\section{Results and Discussion}

\subsection{Catalysts' physical-chemical evolution upon calcination}

We first carried out a systematic DSC-TGA analysis in order to monitor the catalysts' physical-chemical evolution at simulated calcination conditions. At the early stages of calcination, metal nitrate catalytic precursors $\mathrm{Me}\left(\mathrm{NO}_{3}\right)_{2}(\mathrm{Me}=\mathrm{Co}, \mathrm{Ni}, \mathrm{Mg})$ decompose to the corresponding oxides which further react with molybdenum to form molybdate species. The evolution of the different precursors with temperature up to $700{ }^{\circ} \mathrm{C}$ was followed by DSC-TGA experiments (not shown here). The transitions taking place are well described in the literature [19-21] and can be summarized as follows: below $200^{\circ} \mathrm{C}$ citric acid decomposes to give $\mathrm{CO}_{\mathrm{x}}$ and water, leaving a carbonaceous residue that combust at about $400^{\circ} \mathrm{C}$. On the other hand, metal nitrates $\mathrm{Me}\left(\mathrm{NO}_{3}\right)_{2}$ decompose into nitrogen oxides $\left(\mathrm{NO}_{\mathrm{x}}\right)$ and the corresponding oxides $\mathrm{Me}_{\mathrm{x}} \mathrm{O}_{\mathrm{y}}(\mathrm{Me}=\mathrm{Co}, \mathrm{Ni}, \mathrm{Mg})$ at about $400^{\circ} \mathrm{C}$. In the range of calcination temperature between 500 and $750^{\circ} \mathrm{C}$, metal oxides react with molybdenum to form metal molybdates. Excess of molybdenum in these experiments oxidises beyond $500{ }^{\circ} \mathrm{C}$ and forms non-stoichiometric $\mathrm{MoO}_{3-\mathrm{x}}$ oxides, coexisting with the molybdates. Molybdates' phase transitions relevant for MWCNT growth should occur beyond $700{ }^{\circ} \mathrm{C}$. Therefore, the physical-chemical changes taking place in this range of temperatures comprise the focus of the following discussion. 
DSC-TGA thermograms in Figure 1 show sharp endothermic peaks for both types of catalysts: at $758^{\circ} \mathrm{C}$ and $849^{\circ} \mathrm{C}$ for Co-Mo, and at $750{ }^{\circ} \mathrm{C}, 813^{\circ} \mathrm{C}$ and $840{ }^{\circ} \mathrm{C}$ for Ni-Mo. Furthermore, a mass loss of $50 \%$ is observed in the temperature range between $750{ }^{\circ} \mathrm{C}$ and $900{ }^{\circ} \mathrm{C}$, which together with the one observed at temperatures below $750{ }^{\circ} \mathrm{C}$ results in a total mass loss of around $60 \%$ for both catalysts.

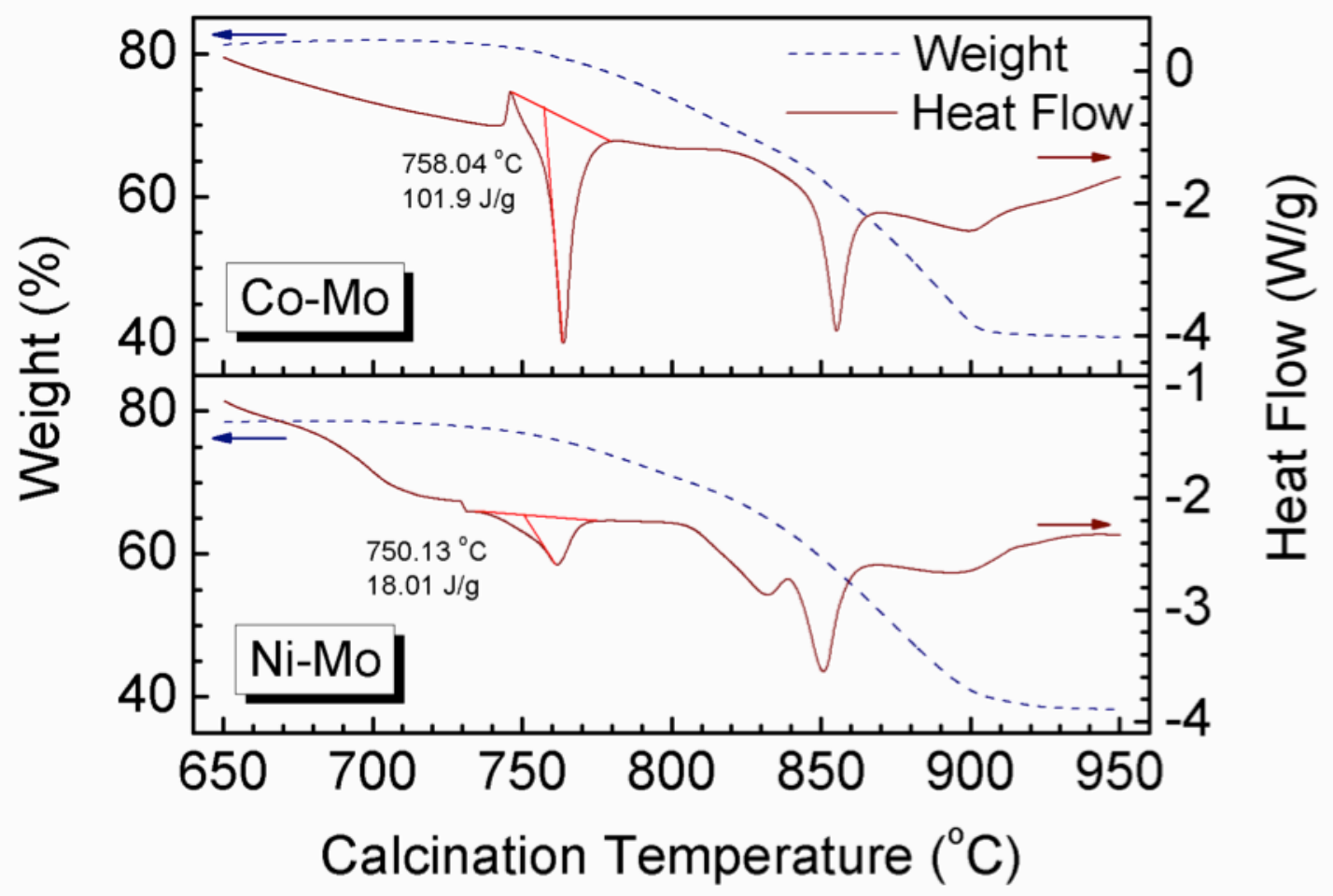

Figure 1. DSC-TGA thermograms of calcination process from $650^{\circ} \mathrm{C}$ to $950^{\circ} \mathrm{C}$ for $\mathrm{Co}-$ Mo and Ni-Mo catalysts. DSC (-), TGA (--).

The catalyst weight drop starting at $750{ }^{\circ} \mathrm{C}$ is attributed to the sublimation of $\mathrm{MoO}_{3-\mathrm{x}}$, formed by oxidation of the non-reacting molybdenum, as mentioned above. Consequently, similar mass losses are observed for both catalysts. Endothermic peaks could be assigned to the melt of a possible eutectic formed by the solid solution of the molybdate phases. Thus, molybdate phase transformations should take place in the vicinity of the endothermic peaks. We therefore selected three calcination temperatures around the first endothermic peak, i.e. $700{ }^{\circ} \mathrm{C}, 750{ }^{\circ} \mathrm{C}$, and $800{ }^{\circ} \mathrm{C}$, to prepare the 
catalysts, and studied their crystalline composition by XRD and Raman spectroscopy. Further endothermic peaks observed around $850^{\circ} \mathrm{C}$ suggest additional phase transitions that will be subject of a forthcoming work.

\subsection{Catalysts' crystalline phase transitions}

Figure 2 shows XRD diffractograms of Co-Mo and Ni-Mo catalysts at calcination temperatures of $700^{\circ} \mathrm{C}, 750^{\circ} \mathrm{C}$, and $800^{\circ} \mathrm{C}$. In general, both types of catalysts show similar XRD features for all the applied calcination conditions. At $700{ }^{\circ} \mathrm{C}$, the $\mathrm{MoO}_{3}$ phase is clearly identified for both Co-Mo and Ni-Mo catalysts. The corresponding diffraction peaks exhibit high intensity in $0 k 0$ planes typical of a preferential crystal growth orientation in a laminar structure related to shear effects in $\mathrm{MoO}_{3}$ at calcination temperatures higher than $600^{\circ} \mathrm{C}[22]$.

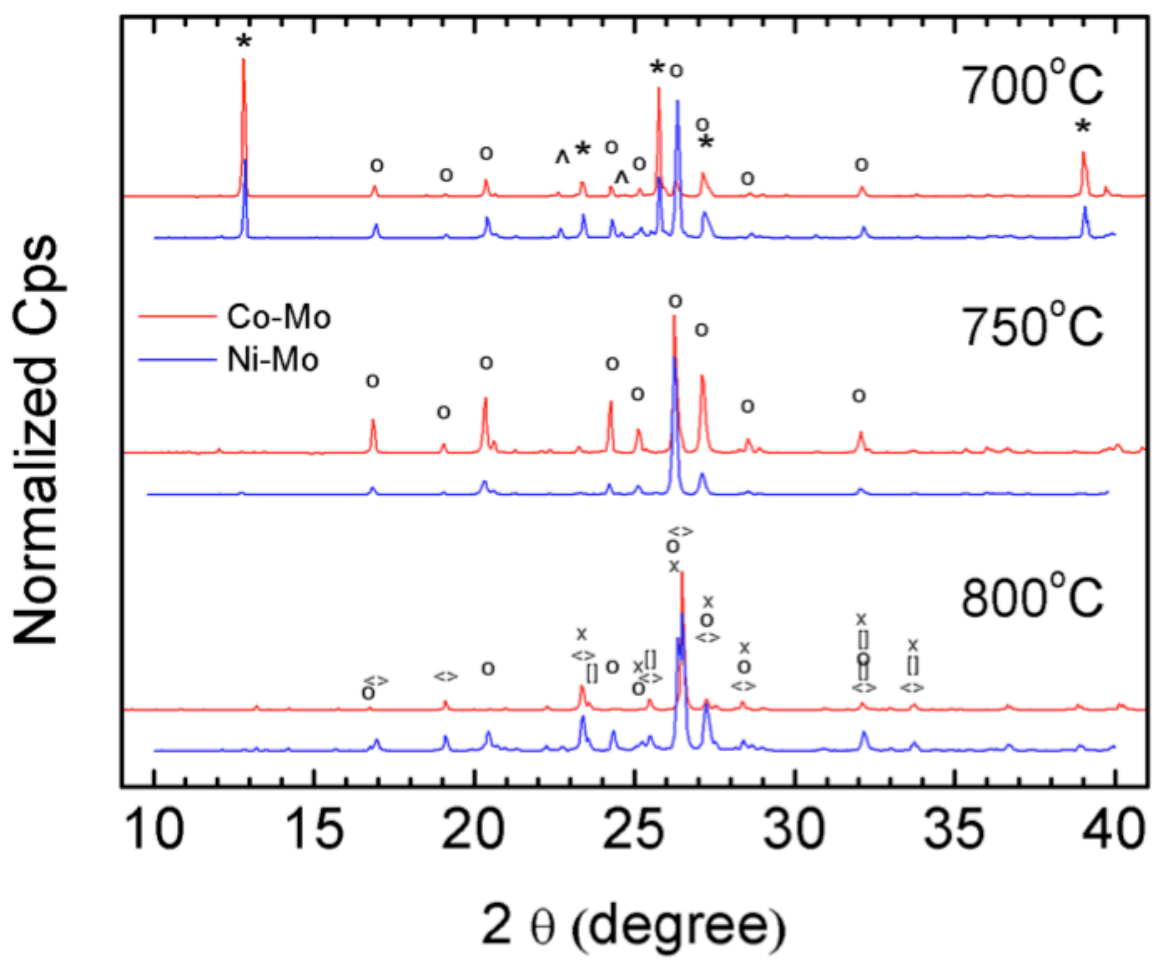

Figure 2. XRD patterns of the Co-Mo and Ni-Mo catalysts obtained at calcination temperatures of $700^{\circ} \mathrm{C}, 750^{\circ} \mathrm{C}$, and $800^{\circ} \mathrm{C}$. Symbols: $\mathrm{MoO}_{3}\left({ }^{*}\right), \mathrm{Mo}_{4} \mathrm{O}_{11}\left({ }^{\wedge}\right), \mathrm{MgMo}_{2} \mathrm{O}_{7}$ (o), $\mathrm{MgMoO}_{4}(<>), \mathrm{CoMoO}_{4}$ ([]), $\mathrm{NiMoO}_{4}$ (x). 
Molybdate phases $\mathrm{Mo}_{4} \mathrm{O}_{11}$ and $\mathrm{MgMo}_{2} \mathrm{O}_{7}$ are also identified although with minor intensities. The molybdenum oxide phases $\left(\mathrm{MoO}_{3}, \mathrm{Mo}_{4} \mathrm{O}_{11}\right)$ are consequence of the molybdenum oxidation to form non-stoichiometric oxides at temperatures above $500{ }^{\circ} \mathrm{C}$ as mentioned above. The formation of the $\mathrm{MgMo}_{2} \mathrm{O}_{7}$ molybdate phase can be explained as reaction product of $\mathrm{MgO}$ with $\mathrm{MoO}_{3}$ occurring in the same temperature range.

$\mathrm{XRD}$ patterns for the catalysts prepared at $750^{\circ} \mathrm{C}$ indicate that $\mathrm{MoO}_{3-\mathrm{x}}$ compounds are not longer identified while $\mathrm{MgMo}_{2} \mathrm{O}_{7}$ is the only recognized phase. The loss of $\mathrm{MoO}_{3-\mathrm{x}}$ is consistent with the molybdenum oxide sublimation observed in the DSC-TGA experiments in this temperature range. Thus, catalysts obtained at a calcination temperature of $750{ }^{\circ} \mathrm{C}$ only comprise a $\mathrm{MgMo}_{2} \mathrm{O}_{7}$ phase whose formation already begins at temperatures below $700^{\circ} \mathrm{C}$.

At calcination temperature of $800{ }^{\circ} \mathrm{C}$, the XRD diffractograms clearly revealed the presence of $\mathrm{MgMoO}_{4}$ phase. However, some differences are noticed between both $\mathrm{Ni}$ Mo, and Co-Mo catalysts. XRD pattern for Ni-Mo catalysts clearly show the preservation of the $\mathrm{MgMo}_{2} \mathrm{O}_{7}$ phase. However this phase is not detected in the Co-Mo catalyst diffractogram. The appearance of the $\mathrm{MgMoO}_{4}$ phase indicates that certain crystal reorganization processes take place after the endothermic melting of the eutectic observed at around $750^{\circ} \mathrm{C}$ by DSC-TGA (see Fig 2). During this reorganization, the $\mathrm{MgMo}_{2} \mathrm{O}_{7}$ phase completely transforms into the $\mathrm{MgMoO}_{4}$ phase for the Co-Mo catalyst.

Peaks corresponding to $\mathrm{NiMoO}_{4}$ and $\mathrm{CoMoO}_{4}$ phases are also identified for Ni-Mo and Co-Mo catalysts respectively. Formation of the metal molybdate phases implies atomic substitution of magnesium by the catalytic metal (cobalt or nickel) within $\mathrm{MgMoO}_{4}$ crystalline domains. In the case of Co-Mo catalyst, the $\mathrm{CoMoO}_{4}$ phase exhibits a XRD pattern with very low intensity. This could be due to both, the low amount of cobalt in 
the overall catalyst composition (see Table 1) and/or the very small cobalt particle size obtained by this method. On the contrary, the $\mathrm{NiMoO}_{4}$ phase in the Ni-Mo catalyst shows much higher XRD intensities.

It finally remains to mention that cobalt and nickel species are not detected at lower calcination temperature possibly because the eutectic point has not been reached and the reorganization of the $\mathrm{MeMoO}_{4}$ phase $(\mathrm{Me}=\mathrm{Co}, \mathrm{Ni})$ has not taken place yet.

Further valuable information about the catalyst evolution during the calcinations process is obtained by probing the chemical coordination of the different molybdenum species by Raman spectroscopy. It is well know that $\mathrm{MoO}_{3}$ has a Mo distorted octahedral coordination, $\alpha-\mathrm{MgMoO}_{4}$ has a distorted tetrahedral coordination and $\mathrm{MgMo}_{2} \mathrm{O}_{7}$ is considered as a polymeric solid with a mixture of both octahedral and tetrahedral coordination geometries [23]. In addition high temperature stable phase $\beta$ $\mathrm{MeMoO}_{4}(\mathrm{Me}=\mathrm{Ni}, \mathrm{Co})$ is isotopic to $\alpha-\mathrm{MgMoO}_{4}$, whereas $\alpha-\mathrm{MeMoO}_{4}$ has a distorted octahedral coordination $[20,22,24]$. The different coordination geometries and chemical bond lengths of the catalyst phases alter the molecule polarizability, and thus the different phases clearly can be identified by distinctive Raman vibrational modes.

Figure 3 shows Raman spectra of the Co-Mo and Ni-Mo catalysts obtained at calcination temperatures of $700^{\circ} \mathrm{C}, 750^{\circ} \mathrm{C}$, and $800^{\circ} \mathrm{C}$. Raman spectra of Co-Mo and NiMo catalysts obtained at $700{ }^{\circ} \mathrm{C}$ exhibit sharp peaks at $993,816,663,334,280 \mathrm{~cm}^{-1}$, which correspond to the characteristic Raman vibrations of $\mathrm{MoO}_{3}$ in octahedral coordination geometry [25]. For catalysts prepared at $750^{\circ} \mathrm{C}$, quite identical Raman spectra were obtained for both Co-Mo and Ni-Mo catalysts underlining the existence of one single phase, namely $\mathrm{MgMo}_{2} \mathrm{O}_{7}$ as identified by XRD. Additionally, the previously observed characteristic $\mathrm{MoO}_{3}$ Raman peaks disappear in agreement with the XRD 
results described before. At a calcination temperature of $800{ }^{\circ} \mathrm{C}$, Raman spectra for CoMo and Ni-Mo catalyst exhibit different features indicating a change in coordination, representative for a phase transition.

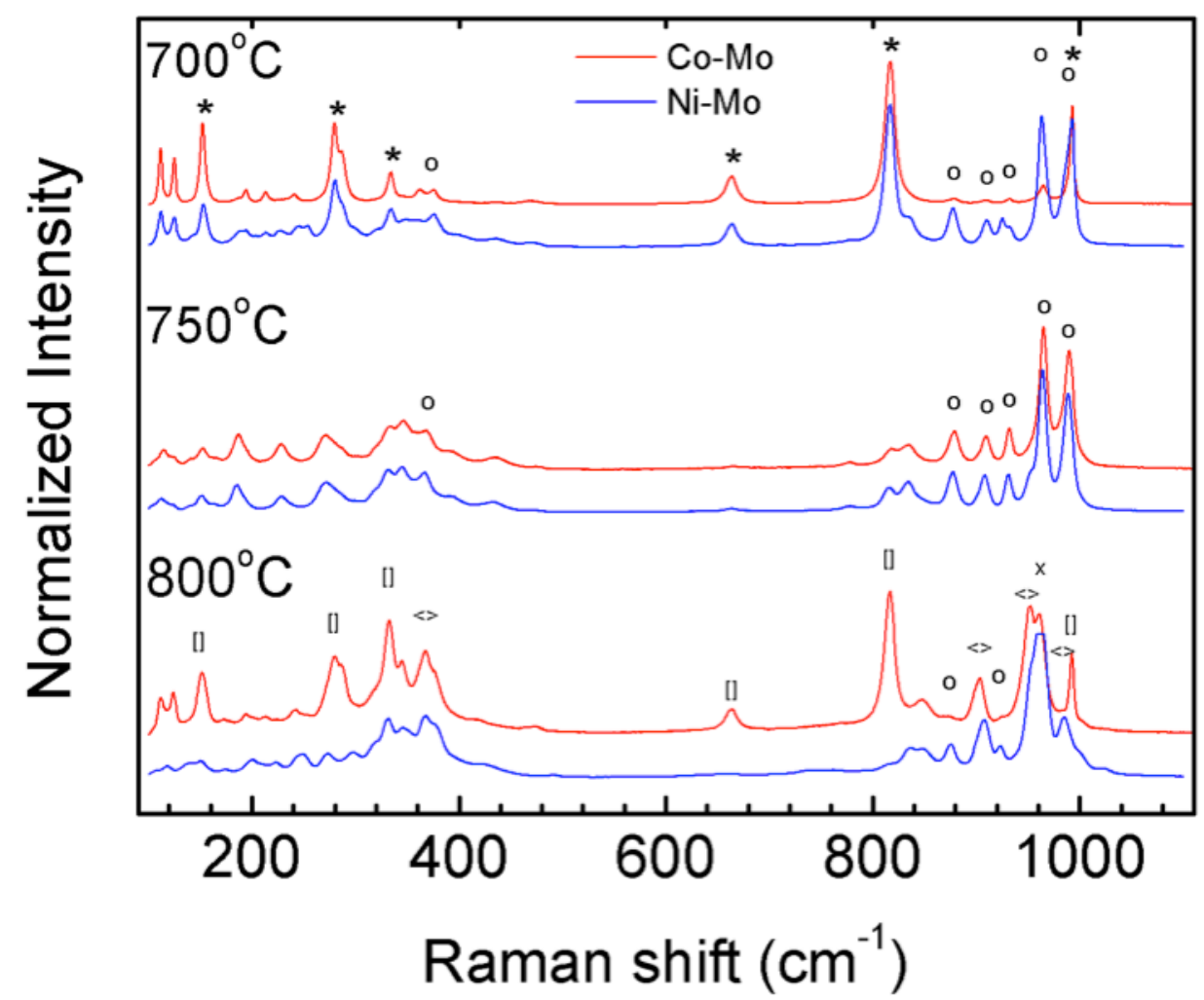

Figure 3. Raman spectra of Co-Mo and Ni-Mo catalysts obtained at calcination temperatures of 700,750 , and $800^{\circ} \mathrm{C}$. Symbols: $\mathrm{MoO}_{3}\left({ }^{*}\right), \mathrm{MgMo}_{2} \mathrm{O}_{7}$ (o), $\mathrm{MgMoO}_{4}$ $(<>), \mathrm{CoMoO}_{4}([]), \mathrm{NiMoO}_{4}(\mathbf{x})$.

In general, Raman spectra show increasing intensity with temperature for the peaks at 963 and $909 \mathrm{~cm}^{-1}$, typical for Mo in tetrahedral coordination geometry. Therefore, Mo tetrahedral coordination associated to $\alpha-\mathrm{MgMoO}_{4}$ is becoming predominant upon increase of the calcination temperature. In particular, for the Ni-Mo catalyst, a superior enhancement of these peaks is clearly observed, which can be explained by the additional contribution of $\mathrm{MgMo}_{2} \mathrm{O}_{7}$ and $\beta-\mathrm{NiMoO}_{4}$ phases, both having tetrahedral 
coordination geometry. However, the Raman spectrum of the Co-Mo catalyst shows that tetrahedral related peaks (963 and $909 \mathrm{~cm}^{-1}$ ) typical for the $\alpha-\mathrm{MgMoO}_{4}$ phase coexist with octahedral related features $\left(993,816,663\right.$, and $\left.280 \mathrm{~cm}^{-1}\right)$ assigned to an $\alpha-$ $\mathrm{CoMoO}_{4}$ phase. It is important to remark that at this calcination temperature the Raman features are broadened and characterized by additional shoulder contributions indicative of multi-phase interactions in distorted crystal geometry of both catalysts $[19,20,24-$ 31]. ${ }^{\circ}$

In order to probe if crystallographic phase transitions eventually could take place at segregated catalysts' domains, EDX mappings were performed for both types of catalyst systems at all calcination temperatures.
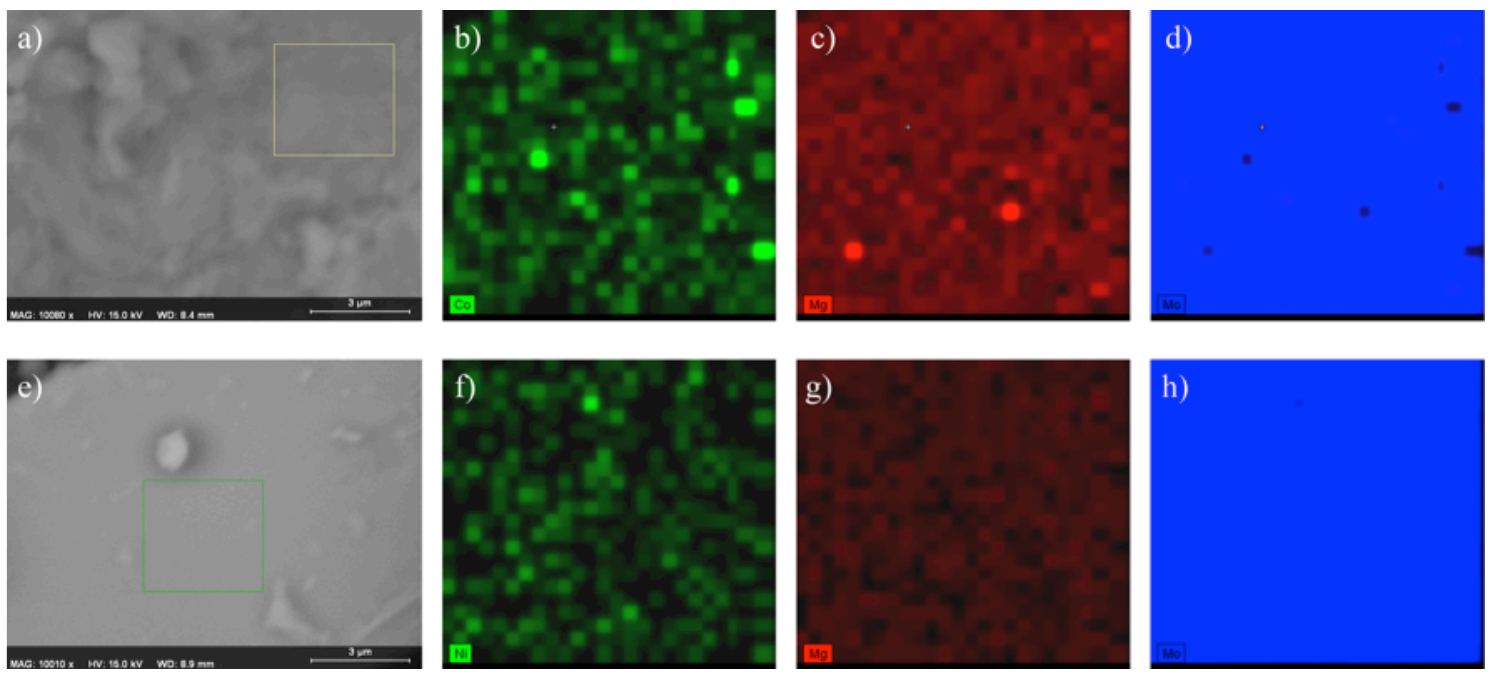

Figure 4. SEM-EDX maps representing the dispersion of molybdenum (blue), magnesium (red), cobalt and nickel (green) of Co-Mo (a-d) and Ni-Mo (e-h) catalysts' selected regions (indicated in a and c) at a calcination temperature of $700^{\circ} \mathrm{C}$.

Figure 4 depicts typical EDX elemental composition maps of both, Co-Mo and Ni-YMo catalysts. It clearly can be seen that all metals are homogeneously dispersed in the continuous Mo phase thus confirming the formation of solid-solid solutions. No changes are observed for different calcination temperatures indicating furthermore that 
phase transitions take place on the overall solid-solid solution without affecting the dispersion of the active metals.

\subsection{Catalysts' platelet-like structure}

Catalyst crystal preferential growth in a laminar structure was inferred by XRD analysis, and subsequently confirmed by electron microscopy. Figure 5 shows SEM and TEM images of both Co-Mo and Ni-Mo catalysts. Here, smooth surfaces arranged in a platelet-like structure are observed by SEM.
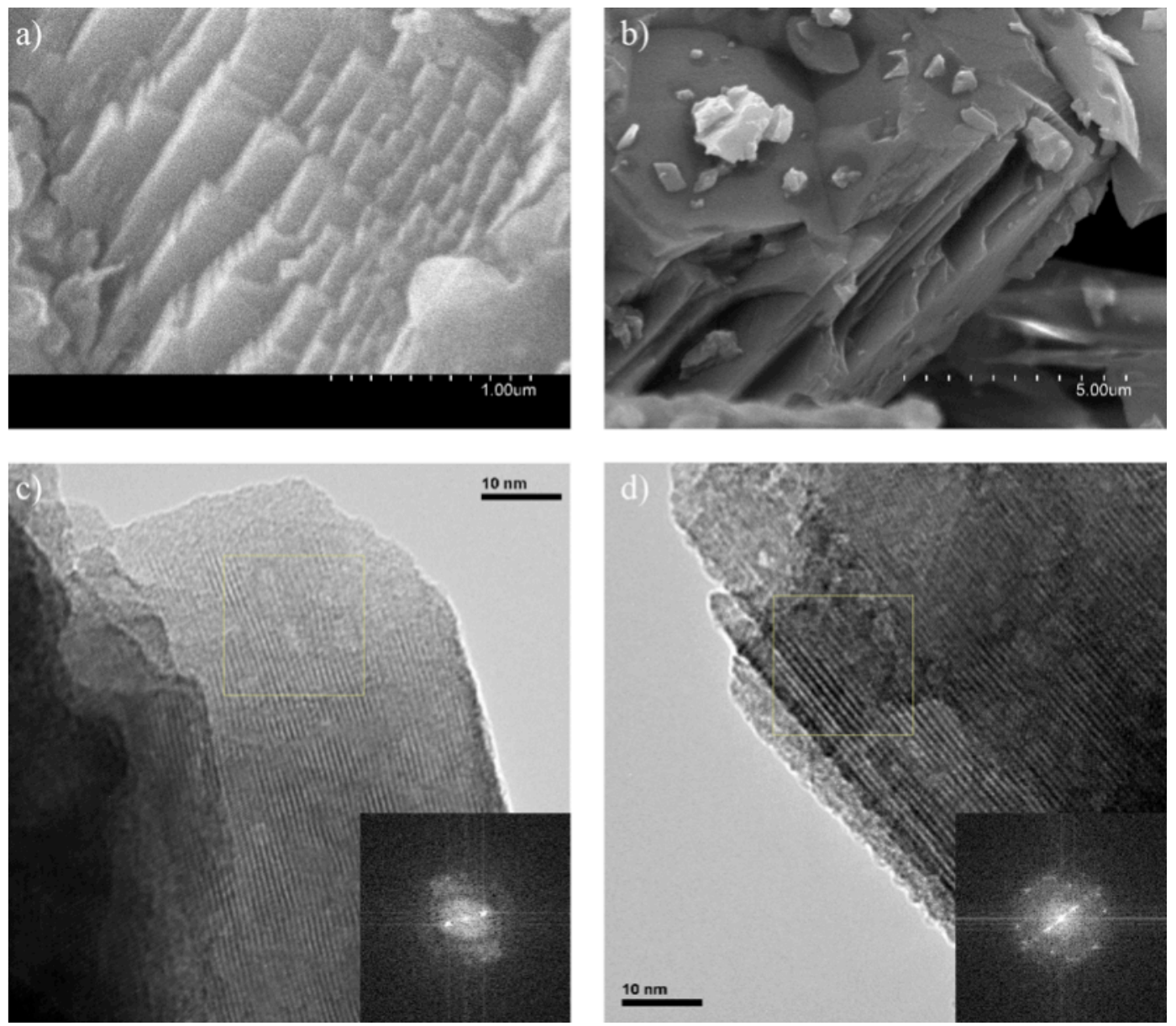

Figure 5. SEM $(a, b)$ and TEM $(c, d)$ micrographs of crystal structure obtained from catalysts $\mathrm{Co}-\mathrm{Mo}(\mathrm{a}, \mathrm{c})$ and $\mathrm{Ni}-\mathrm{Mo}(\mathrm{b}, \mathrm{d})$ at a calcination temperature of $800{ }^{\circ} \mathrm{C}$. Insets show Fast Fourier Transformation images of the selected region of catalyst platelets.

A highly crystalline laminar structure is also clearly recognizable from TEM images and Fast Fourier Transformation analyses. In-plane preferential crystal growth in the form 
of thin parallel sheets can be seen, especially at the edges of the catalytic particles. Additionally, nitrogen adsorption isotherms reveal surface areas below $2 \mathrm{~m}^{2} / \mathrm{g}$ indicative of non-porous systems. Therefore, the observations consistently evidence the formation of non-porous catalysts systems having a platelet-like morphology.

\subsection{MWCNT production and characterization}

The aforementioned results clearly demonstrate that the calcination process strongly influences the formation of the solid-solid molbydate solutions. More specifically, the calcination temperature is the key to develop a specific phase. In the following the influence of the catalyst crystallographic phase on the production of MWCNT by CVD is evaluated.

Table 2. MWCNT production yields and main catalysts crystallographic phases at each catalyst calcination temperature.

\begin{tabular}{|c|c|c|c|}
\hline $\begin{array}{l}\text { Catalyst } \\
\text { type }\end{array}$ & $\begin{array}{c}\text { Calcination } \\
\text { temperature }\left({ }^{\circ} \mathrm{C}\right)\end{array}$ & Crystallographic phase & $\begin{array}{c}\text { Yield } \\
\text { (wWt.\%)* } \%\end{array}$ \\
\hline Co-Mo & 700 & $\mathrm{MoO}_{3}, \mathrm{MgMo}_{2} \mathrm{O}_{7}, \mathrm{Mo}_{4} \mathrm{O}_{11}$ & 1834 \\
\hline Ni-Mo & 700 & $\mathrm{MoO}_{3}, \mathrm{MgMo}_{2} \mathrm{O}_{7}, \mathrm{Mo}_{4} \mathrm{O}_{11}$ & 1190 \\
\hline Co-Mo & 750 & $\mathrm{MgMo}_{2} \mathrm{O}_{7}$ & 2686 \\
\hline Ni-Mo & 750 & $\mathrm{MgMo}_{2} \mathrm{O}_{7}$ & 2106 \\
\hline Co-Mo & 800 & $\mathrm{Co}_{\mathrm{x}} \mathrm{Mg}_{1-\mathrm{x}} \mathrm{MoO}_{4}$ & 3064 \\
\hline Ni-Mo & 800 & $\mathrm{MgMo}_{2} \mathrm{O}_{7}, \mathrm{Ni}_{\mathrm{x}} \mathrm{Mg}_{1-\mathrm{x}} \mathrm{MoO}_{4}$ & 3002 \\
\hline \multicolumn{4}{|c|}{$*$ Yield $_{\text {MWCNT }}(w t \%)=\left(\operatorname{mass}_{\text {MWCNT }}+\right.$ mass $\left._{\text {Catalyst }}\right) /$ mass $_{\text {Catalyst }} * 100$} \\
\hline
\end{tabular}

High yields of MWCNTs are obtained by decomposition of methane in the presence of all the prepared sol-gel catalysts (see Table 2). In general Co-Mo catalysts show higher 
catalytic performance than Ni-Mo catalysts, except for calcination treatments at $800{ }^{\circ} \mathrm{C}$ where both catalysts produce similar yields. It is also important to highlight that the highest yields directly correlate with a higher calcination temperature, and thus with the presence of the $\mathrm{MgMoO}_{4}$ crystallographic phase in the catalyst. This again underlines the importance of the catalyst preparation conditions for the stabilization of certain catalytic phases $\left(\mathrm{Co}_{\mathrm{x}} \mathrm{Mg}_{1-\mathrm{x}} \mathrm{MoO}_{4}\right.$ and $\left.\mathrm{Ni}_{\mathrm{x}} \mathrm{Mg}_{1-\mathrm{x}} \mathrm{MoO}_{4}\right)$ and its relevance for the enhancement of MWCNT production yields.
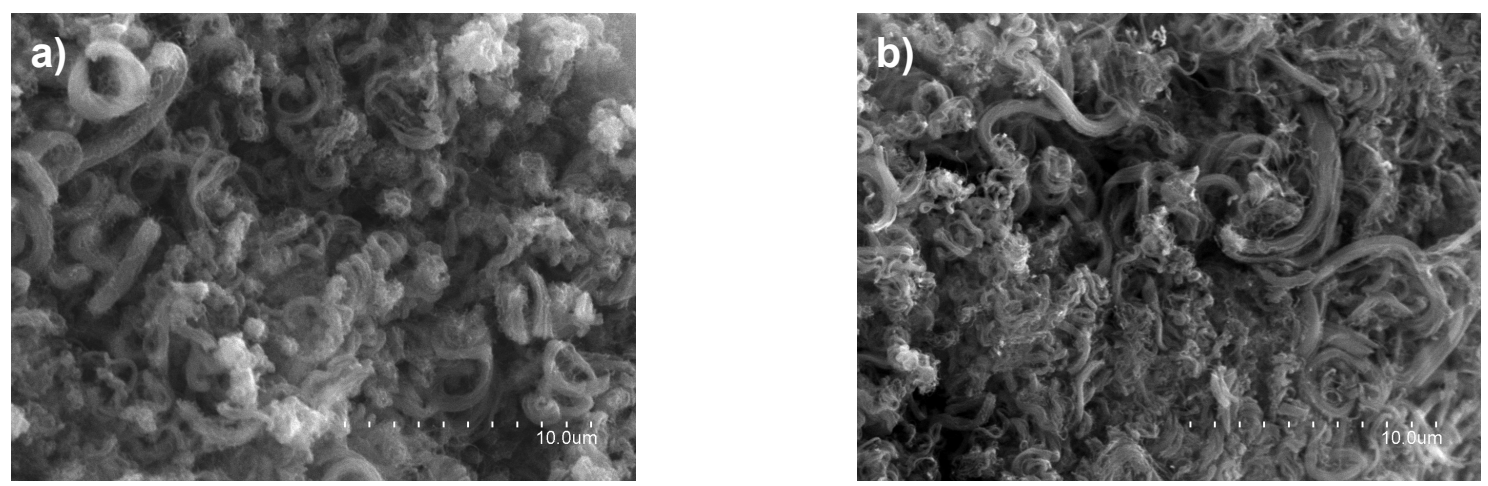

Figure 6. SEM micrographs of MWCNT materials obtained with Co-Mo (a), Ni-Mo (b) catalysts.

SEM images of the as-synthesized carbon products (Figure 6) gives evidence of a homogeneous material consisting of high density of large curved bundles of several micrometers in length and several hundreds of nanometers in diameter. No noteworthy differences with respect to the type of metal and the calcination temperature are observed. The bundles consist of thin (3-5 nm) MWCNTs, and negligible amount of amorphous carbon (Figure 7). In general, Ni-Mo catalysts produce somewhat thicker MWCNT bundles ranging from $400 \mathrm{~nm}$ to $1 \mu \mathrm{m}$, in contrast to Co-Mo catalysts, which lead to average MWCNT bundle diameters below $300 \mathrm{~nm}$. 
Catalytic particles were in general difficult to find due to the high MWCNT yields obtained (elemental analyses indicate overall catalysts amounts of about $1 \mathrm{wt} \%$ in the produced MWCNT materials. However when observed, catalyst particles commonly appear as larger fragments attached to one extreme of MWCNT bundles. Interestingly, their
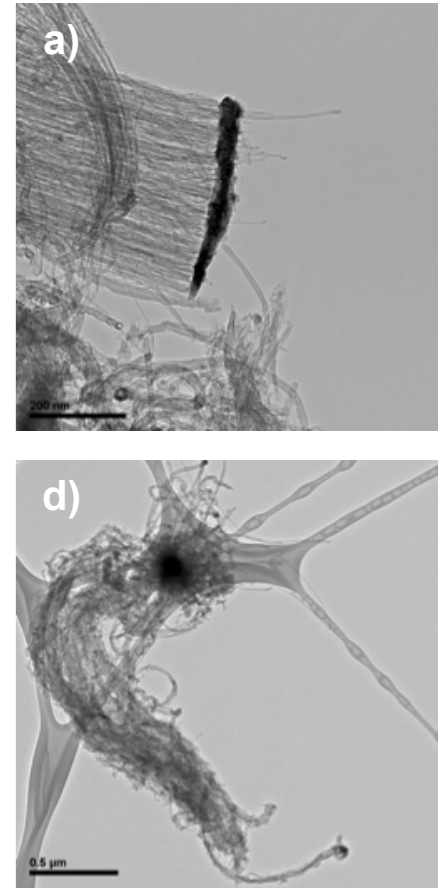
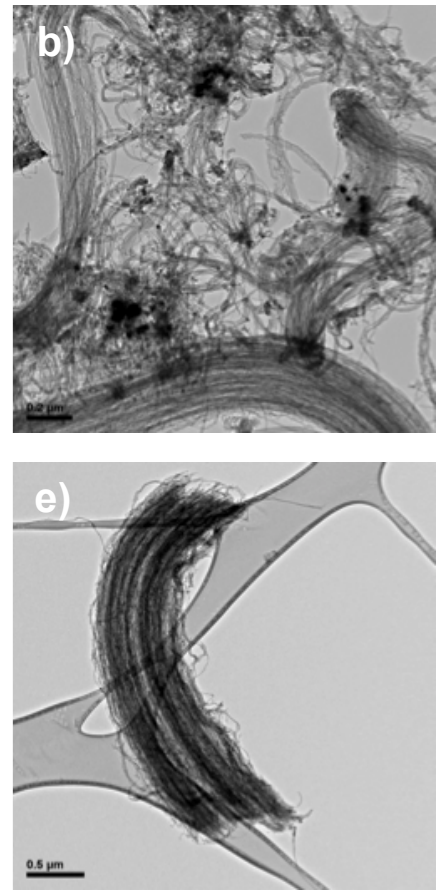
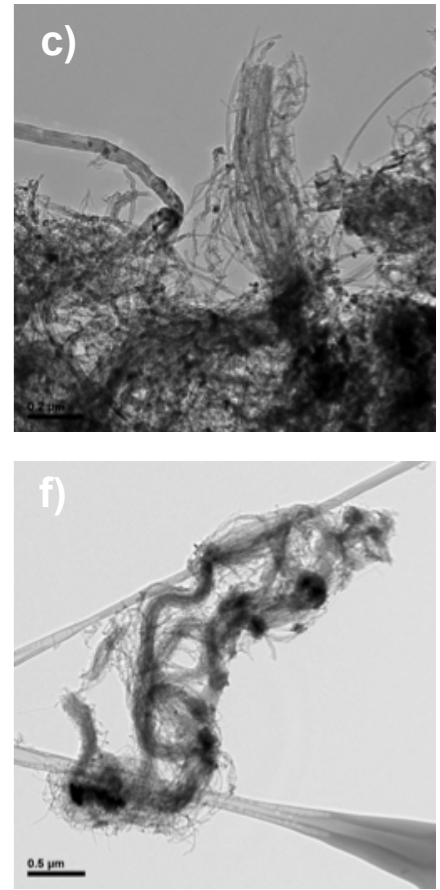

Figure 7. TEM micrographs of MWCNTs obtained from catalysts Co-Mo (a-c) and NiMo (d-f).

lengths scale correlates to the size of the MWNCNT bundle diameters (see Fig. 7a as example), which could be associated with a common starting growing plane for MWCNT growth.

For all the produced materials, no RBM modes are detected in the corresponding Raman spectra (Figure 8), thus indicating the absence of SWNTs. However, typical D and $\mathrm{G}$ bands for MWCNTs are observed at $1400 \mathrm{~cm}^{-1}$ and $1600 \mathrm{~cm}^{-1}$, respectively. Looking at the intensity ratios of the $\mathrm{D}$ to $\mathrm{G}$ bands, no significant tendencies as a function of calcination temperature are found. Nevertheless, at all temperatures, MWCNTs produced by Co-Mo catalysts are characterized by higher $I_{G} / I_{D}$ ratios, 
indicative of higher degree of crystallinity compared to Ni-Mo catalyst systems. Even more important, in the region from 100 to $1000 \mathrm{~cm}^{-1}$ none of the sharp peaks typical for the catalyst (see Figure 3) can be seen anymore. This once more shows, that catalyst materials are negligible in the produced materials, explains the difficulties to find any catalyst material in the final sample, and underlines the high production yields obtained.

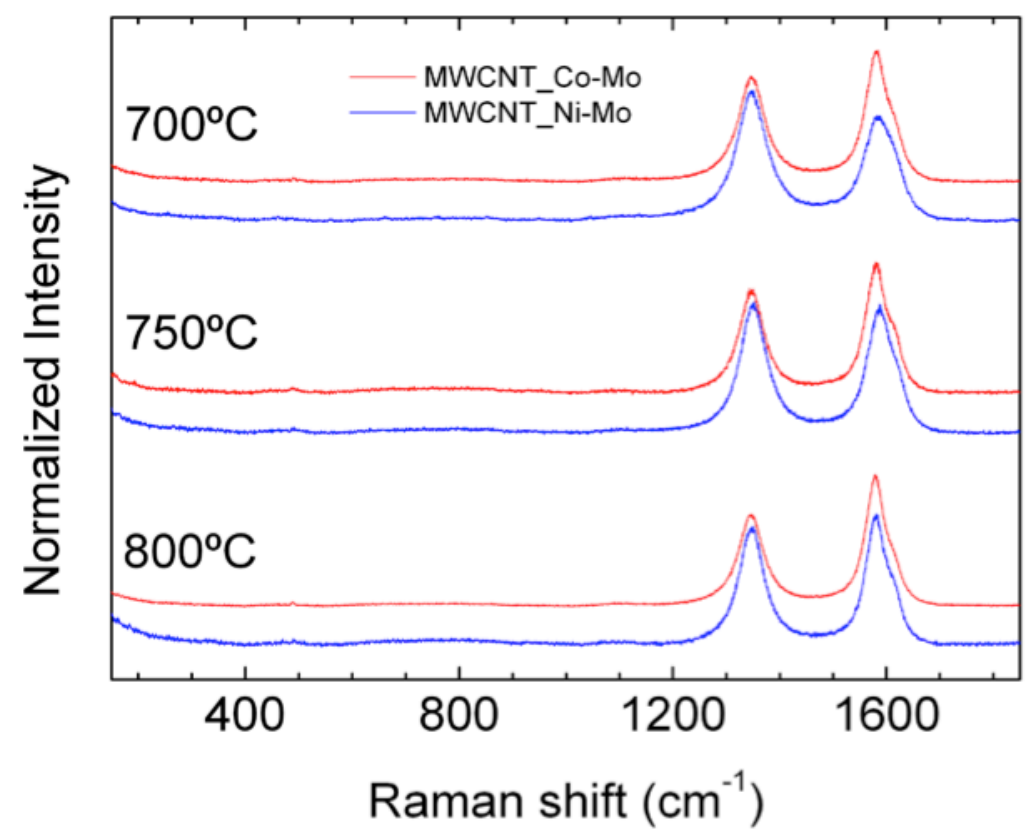

Figure 8. Raman spectra of MWCNT materials produced by Co-Mo and Ni-Mo catalysts calcinated at $700^{\circ} \mathrm{C}, 750^{\circ} \mathrm{C}$ and $800^{\circ} \mathrm{C}$.

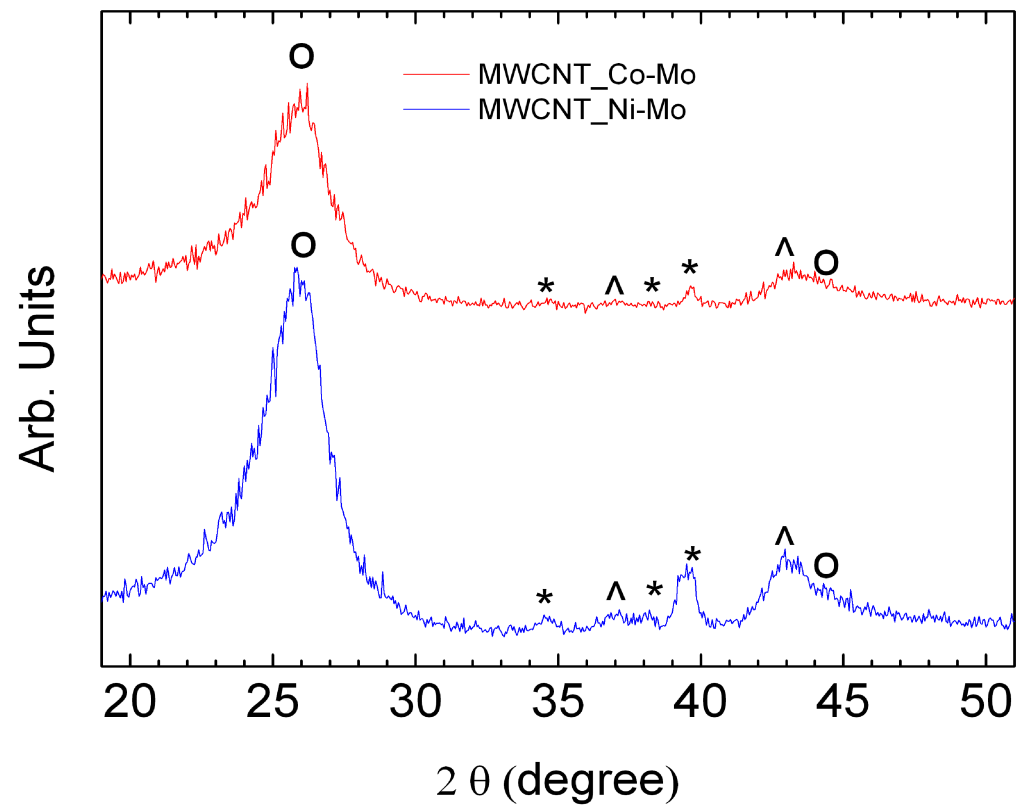

Figure 9. XRD patterns of MWCNT materials produced by Co-Mo (top) and Ni-Mo (down) catalysts at a calcination temperature of $700^{\circ} \mathrm{C}$. Symbols: $\mathrm{Mo}_{2} \mathrm{C}\left({ }^{*}\right), \mathrm{MgO}\left({ }^{\wedge}\right)$, MWCNT (o). 
X-Ray diffractograms of MWCNT produced by Ni-Mo and Co-Mo catalysts (Figure 9) show the typical broad peaks of MWCNTs as well as some minor peaks of molybdenum carbide and magnesium oxide. None of the sharp features typical for $\mathrm{Ni}$ or Co phases (see Figure 2) can be detected. Again, this is consistent with the Raman and TEM results confirming the negligible amount of metal particles in the final sample materials.

\subsection{MWCNT growth mechanism}

In previous sections, we have shown how an increase of the calcination temperature leads to crystallographic changes related to the formation and stabilization of crystallographic phases $\mathrm{Me}_{\mathrm{x}} \mathrm{Mg}_{1-\mathrm{x}} \mathrm{MoO}_{4}(\mathrm{Me}=\mathrm{Co}$, or Ni), relevant for the improvement of MWCNT production. Furthermore, the sol-gel method used here produces nonporous catalysts with laminar morphology, which are highly favourable for high yield MWCNT production. This is quite intriguing if one takes into account the general consideration that porous catalysts systems favour the dispersion state of the active catalyst nanoparticles, avoid massive sintering during the CVD process, and thus provide high surface areas and catalytic performance towards enhanced nanotube growth [32-36].

Having a non-porous catalyst system leading to high MWCNT yield production thus brings into focus its layered morphology, which apparently is an additional important factor to be taken into account. This will be discussed in the following by presenting a 
growth mechanism for MWNCTs, which consistently explains the experimental findings of our work (Figure 10).

Four essential steps are considered. Step 1: Before the CVD reaction, $\mathrm{Me}_{\mathrm{x}} \mathrm{Mg}_{1-\mathrm{x}} \mathrm{MoO}_{4}$ molybdates form a sol-sol solution. Once the reaction temperature is reached $\left(1000^{\circ} \mathrm{C}\right)$, a hydrogen flow is introduced into the reactor to reduce metal atoms $(\mathrm{Co}, \mathrm{Ni})$, which immediately arrange into catalytic active metal nanoparticles. Step 2: Reduced molybdenum oxide, $\mathrm{MoO}_{2}$, is formed simultaneously and stabilises active metal nanoparticles, thus avoiding sintering into large metal cluster during the reduction process. Subsequently, methane introduced in the system starts to catalytically decompose, allowing carburization of the active metals and the available molybdenum as unstable and stable carbides, respectively. The correspondingly formed carbides act as a carbon sink, and regulate the carbon diffusion during the nucleation process. Step 3: Once saturation of unstable metal carbides is reached, nucleation stops and carbon precipitates in the form of MWCNTs in a typical base growth mechanism whereas the catalytic nanoparticles are still strongly attached to the support. Step 4: The directional mass diffusion of carbon into the form of MWCNTs at each nucleating active catalytic nanoparticle now may induce simultaneous stress between the layer-layer interfaces of the laminar catalytic system. These continued interlayer tensions could overcome weak interlayer attractive Van-der-Waals interactions leading to the exfoliation of individual layer-based catalyst domains. 


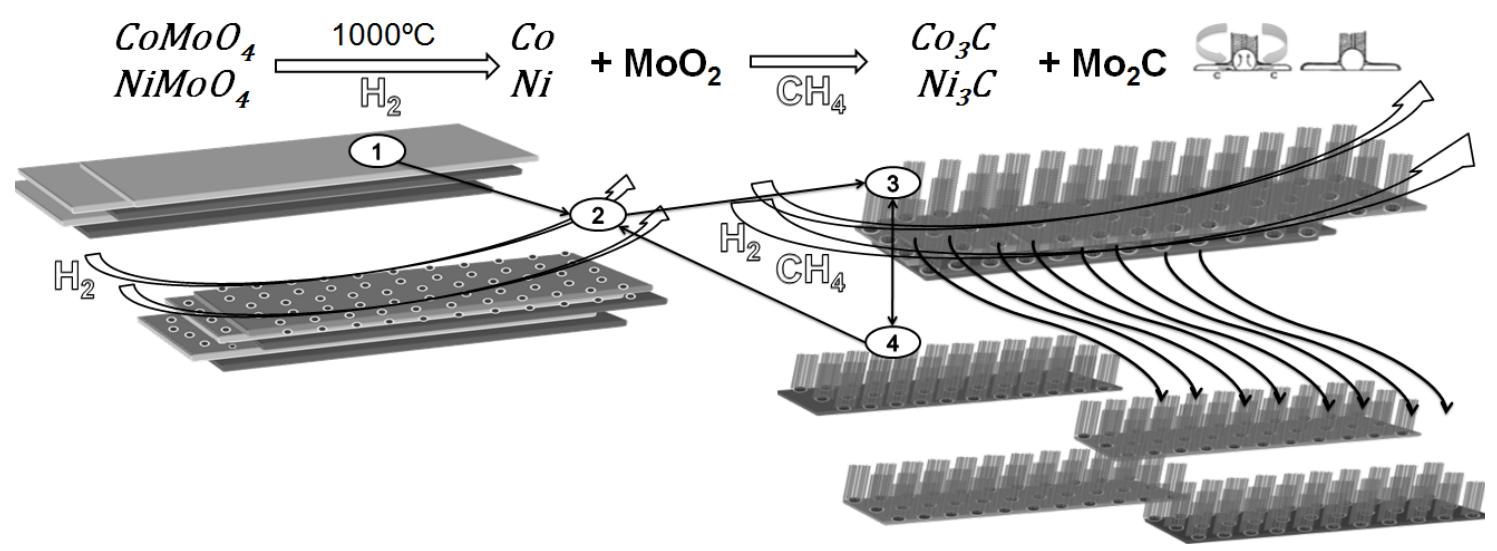

Figure 10. Proposed growth mechanism in 4 steps: 1) Reduction to form catalytic active metal clusters. 2) Stabilization and nucleation of metal carbide nanoparticles. 3) MWCNT growth. 4) Exfoliation of platelet-like catalyst structure.

The exfoliation process then exposes fresh catalyst, and the cycle is repeated over and over again. In this way, all the potential nucleation sites of the layered catalyst system can effectively contribute to the formation of MWCNT in high yields. This growth mechanism is in agreement with the observation of wide MWCNT bundles attached at one extreme to catalyst fragments whose sizes are related to the bundle diameters. Large bundle diameters would be formed by Van-der-Waals interactions between thin MWCNTs, which are growing very densely due to the proximity of the nucleation sites within the catalyst fragments. Furthermore, the high aspect ratio of the produced MWCNTs underlines the high activity of the exfoliated catalyst domains allowing MWCNTs to easily reach micrometer lengths. In addition, XRD and Raman characterization of the produced materials confirm that the samples are composed (almost) exclusively of MWCNTs. The proposed model thus successfully explains MWCNT high yield production for these non-porous platelet-like catalyst systems.

Finally, the proper catalyst design also elucidates the effect of calcinations temperature on the MWCNT yields. At calcinations temperatures of $700{ }^{\circ} \mathrm{C}$ and $750{ }^{\circ} \mathrm{C}$ the important $\mathrm{Me}_{\mathrm{x}} \mathrm{Mg}_{1-\mathrm{x}} \mathrm{MoO}_{4}(\mathrm{Me}=\mathrm{Ni}, \mathrm{Co})$ phase has not formed and massive sintering during nucleation becomes dominant due to a sub-optimal surface stabilization of the 
catalytic active metals $\mathrm{Ni}$ and $\mathrm{Co}$. Thus, this process limits the availability of active catalytic sites suitable for MWCNT growth, as well as the efficiency of the exfoliation cycle. On the contrary, deactivation is considerably diminished by the good dispersion and stability of active metal nanoparticles achieved once the $\mathrm{Me}_{\mathrm{x}} \mathrm{Mg}_{1-\mathrm{x}} \mathrm{MoO}_{4}(\mathrm{Me}=\mathrm{Ni}$, Co) phases are formed at catalyst calcinations temperature of $800{ }^{\circ} \mathrm{C}$.

\section{Conclusions}

Using sol-gel techniques, we have designed a set of non-porous platelet-like catalyst systems based on nickel and cobalt as active catalysts embedded in a magnesium oxide matrix. These have been used for the CVD growth of MWCNTs. By carefully controlling the calcination temperature during the catalyst preparation, we have established a relation between catalyst design and high yield MWCNT production. We have demonstrated that at a calcination temperature of $800{ }^{\circ} \mathrm{C}$ catalysts stabilise in a crystallographic phase of $\mathrm{Me}_{\mathrm{x}} \mathrm{Mg}_{1-\mathrm{x}} \mathrm{MoO}_{4}(\mathrm{Me}=\mathrm{Ni}, \mathrm{Co})$. We show that this phase is responsible for a high stabilization degree of the homogeneously dispersed active catalyst species, i.e. $\mathrm{Ni}$ and $\mathrm{Co}$, and results in the formation of large bundles of MWCNTs in yields of more than $3000 \mathrm{wt} \%$ with respect to the initial catalyst. Finally, we propose a growth model based on the continuous exfoliation of platelet-like catalyst systems explaining the high yield MWCNT production achieved by non-porous catalysts. Our findings provide important insights for the rational design of highly active catalyst systems of great interest towards an effective and low-cost large-scale MWCNT production. 


\section{Acknowledgements}

Financial supports from Spanish Ministry of Science and Innovation (MICINN) and the European Regional Development Fund (ERDF) under project MAT2007-66927-CO201, from the Government of Aragon under projects DGA-T66 CNN and DGAPI086/08, as well as from CSIC-CITMA-CEAC Project are acknowledged. J.D.N. thanks CSIC for his JAE-CSIC PhD-grant. The use of TEM facilities (Servicios de Apoyo a la Investigación) of the University of Zaragoza is acknowledged

\section{References}

[1] Dresselhaus MS, Dresselhaus G, Avouris Ph. Carbon Nanotubes: Synthesis, Structure, Properties and Applications, Topics in Applied Physics, Vol. 80, Berlin: Springer; 2001.

[2] Terrones M. Carbon nanotubes: synthesis and properties, electronic devices and other emerging applications. International Materials Reviews 2004; 49, 6: 325-27.

[3] Morançais A, Caussat B, Kihn Y, Kalck P, Plee D, Gaillard P, et al. A parametric study of the large-scale production of multi-walled carbon nanotubes by fluidized bed catalytic chemical vapor deposition. Carbon 2007; 45: 624-635.

[4] Zhang Q, Zhaoa MQ, Huanga JQ, Niea JQ, Wei F. Mass production of aligned carbon nanotube arrays by fluidized bed catalytic chemical vapor deposition. Carbon 2010; 48: 1196-1209.

[5] Esconjaureguia S, Whelana CM, Maexb K. The reasons why metals catalyze the nucleation and growth of carbon nanotubes and other carbon nanomorphologies. Carbon 2009; 47: $659-669$. 
[6] Kumar M, Ando Y. Chemical vapor deposition of carbon nanotubes: A review on growth mechanism and mass production. Journal of Nanoscience and Nanotechnology 2010; 10: 3739-3758.

[7] Balbuena PB, Zhao J, Huang S, Wang Y, Sakulchaicharoen N, Resasco DE. Role of the catalyst in the growth of single-wall carbon nanotubes. Journal of Nanoscience and Nanotechnology 2006; 6: 1-12.

[8] Philippe R, Caussat B, Falqui A, Kihn K, Kalck P, Bordere S, et al. An original growth mode of MWCNTs on alumina supported iron catalysts. Journal of Catalysis 2009; 263: 345-358.

[9] Xu Y, Li Z, Dervishi E, Saini V, Cui J, Biris AR, et al. Surface area and thermal stability effect of the $\mathrm{MgO}$ supported catalysts for the synthesis of carbon nanotubes. Journal of Material Chemistry 2008; 18: 5738-5745.

[10] Lolli G, Zhang L, Balzano L, Sakulchaicharoen N, Tan Y, Resasco DE. Tailoring $(n, m)$ structure of single-walled carbon nanotubes by modifying reaction conditions and the nature of the support of CoMo catalysts. Journal of Physical Chemistry B 2006; 110: 2108-2115

[11] Lamouroux E, Serp P, Kalck P. Catalytic routes towards single wall carbon nanotubes. Catalysis reviews 2007; 49: 341-405.

[12] Ning Y, Zhang X, Wang Y, Sun Y, Shen L, Yang X, et al. Bulk production of multi-wall carbon nanotube bundles on sol-gel prepared catalyst. Chemical Physics letters 2002; 366: 555-560.

[13] Dupuis AC. The catalyst in the CCVD of carbon nanotubes-a review. Progress in Materials Science 2005; 50: 929-96. 
[14] Li Y, Zhang XB, Tao XY, Xu JM, Huang WZ, Luo JH, et al. Mass production of high-quality multi-walled carbon nanotube bundles on a $\mathrm{Ni} / \mathrm{Mo} / \mathrm{MgO}$ catalyst. Carbon 2005; 43: 295-301.

[15] Noda S, Sugime H, Osawa T, Tsuji Y, Chiashi S, Murakami Y, et al. A simple combinatorial method to discover Co-Mo binary catalysts that grow vertically aligned single-walled carbon nanotubes. Carbon 2006; 44: 1414-1419.

[16] Moisala A, Nasibulin AG, Kauppinen EI. The role of metal nanoparticles in the catalytic production of single-walled carbon nanotubes - a review. Journal of Physics: Condensed Matter 2003; 15: S3011-3036.

[17] Pérez-Mendoza M, Vallés C, Maser WK, Martínez MT, Benito AM. Influence of molybdenum on the chemical vapour deposition production of carbon nanotubes. Nanotechnology 2005; 16: S224-S229.

[18] Pérez-Mendoza M, Vallés C, Maser WK, Martínez MT, Langlois S, Sauvajol JL. et al. Ni-Y/Mo catalyst for the large-scale CVD production of multi-wall carbon nanotubes. Carbon 2005; 43: 3002-3039.

[19] Tsuzuki A, Kani K, Watari K, Torii Y. Phase relations in the $\mathrm{MoO}_{3}-\mathrm{MgMoO}_{4}$ system. Journal of Materials Science letters 1992; 11: 334-335.

[20] Oganowski W, Hanuza J, Jezowska-trzebiatowska B, Wrzyszcz J. Physicochemical properties and structure of $\mathrm{MgMoO}_{4}-\mathrm{MoO}_{3}$ catalysts. Journal of Catalysis 1975, 39: 161-172.

[21] Van Landuyt J. Shear structures and crystallographic shear propagation. Journal de physique 1974; 12, 35: C7-53. 
[22] Dieterle M. In situ resonance Raman studies of molybdenum oxide based selective oxidation catalysts. Technical University of Berlin, PhD Thesis, 2001, p. $16-17$.

[23] Greenwood NN, Earnshaw A. Chemistry of the Elements. 2nd ed. Oxford: Butterworth-Heinemann, 1997

[24] Maione A, Devillers M. Solid solutions of Ni and Co molybdates in silicadispersed and bulk catalysts prepared by sol-gel and citrate methods. Journal of Solid State Chemistry 2004; 177: 2339-2349.

[25] Chang SC, Leugers MA, Bare SR. Surface chemistry of magnesium oxidesupported molybdenum oxide: an in situ Raman spectroscopic study. Journal of Physical Chemistry 1992; 96:10358-10365.

[26] Pereira LG, Soledade LEB, Ferreira JM, Limab SJG, Fernandes VJ Jr, Aráujo AS, et al. Influence of doping on the preferential growth of $\alpha-\mathrm{MoO}_{3}$. Journal of Alloys and Compounds 2008; 459: 377-385.

[27] Abdel-Dayem HM. Dynamic phenomena during reduction of $\alpha-\mathrm{NiMoO}_{4}$ in different atmospheres: In-Situ thermo-Raman spectroscopy study. Ind. Eng. Chem. Res. 2007, 46: 2466-2472.

[28] Kaddouria A, Tempestib E, Mazzocchia C. Comparative study of $\beta$-nickel molybdate phase obtained by conventional precipitation and the sol-gel method. Materials Research Bulletin 2004; 39: 695-706.

[29] Cheng CP, Schrader GL. Characterization of supported molybdate catalysts during preparation using laser raman spectroscopy. Journal of Catalysis 1979; 60:276-294. 
[30] Rodriguez JA, Chaturvedi S, Hanson JC, Albornoz A, Brito JL. Electronic properties and phase transformations in $\mathrm{CoMoO}_{4}$ and $\mathrm{NiMoO}_{4}$ : XANES and timeresolved synchrotron XRD studies. Journal of Physical Chemistry B 1998; 102: $1347-1355$.

[31] Xiao TC, York APE, Al-Megren H, Williams CV, Wang HT, Green MLH. Preparation and characterization of bimetallic cobalt and molybdenum carbides. Journal of Catalysis 2001; 202: 100-109.

[32] Resasco DE, Alvarez WE, Pompeo F, Balzano L, Herrera JE, Kitiyanan B, et al. A scalable process for production of single-walled carbon nanotubes (SWNTs) by catalytic disproportionation of $\mathrm{CO}$ on a solid catalyst. Journal of Nanoparticle Research 2002; 4: 131-136.

[33] Jia Y, Heb L, Kong L, Liub J, Guob Z, Meng F, et al. Synthesis of close-packed multi-walled carbon nanotube bundles using Mo as catalyst. Carbon 2009; 47: $1652-1658$.

[34] Li Y, Zhang X, Tao X, Xu J, Chen F, Huang W, et al. Growth mechanism of multi-walled carbon nanotubes with or without bundles by catalytic deposition of methane on Mo/MgO. Chemical Physics Letters 2004; 386: 105-110.

[35] Tian Y, Yang H, Cui Y, Zhana S, Chen Y. A multi-stage growth model leading to high-yield production of carbon nanotubes. Chem. Commun; 2008, 3299-3301.

[36] Bajwa N, Li X, Ajayan PM, Vajtai R. Mechanisms for Catalytic CVD Growth of Multiwalled Carbon Nanotubes. Journal of Nanoscience and Nanotechnology 2008; 8: 6054-6064. 


\section{Table Captions}

Table 1: Catalyst metal loadings (at \%).

Table 2: MWCNT production yields and main catalysts crystallographic phases at each catalyst calcination temperature.

\section{Figure Captions}

Figure 1. DSC-TGA thermograms of calcination process from $650^{\circ} \mathrm{C}$ to $950^{\circ} \mathrm{C}$ for $\mathrm{Co}-$ Mo and Ni-Mo catalysts. DSC (-), TGA (--).

Figure 2: XRD patterns of the Co-Mo, and Ni-Mo catalysts obtained at calcination temperatures of $700^{\circ} \mathrm{C}, 750^{\circ} \mathrm{C}$, and $800^{\circ} \mathrm{C}$. Symbols: $\mathrm{MoO}_{3}\left(^{*}\right), \mathrm{Mo}_{4} \mathrm{O}_{11}\left({ }^{\wedge}\right), \mathrm{MgMo}_{2} \mathrm{O}_{7}$ (o), $\mathrm{MgMoO}_{4}(<>), \mathrm{CoMoO}_{4}([]), \mathrm{NiMoO}_{4}(\mathrm{x})$.

Figure 3: Raman spectra of Co-Mo and Ni-Mo catalysts obtained at calcination temperatures of 700,750 , and $800^{\circ} \mathrm{C}$. Symbols: $\mathrm{MoO}_{3}(*), \mathrm{MgMo}_{2} \mathrm{O}_{7}$ (o), $\mathrm{MgMoO}_{4}$ $(<>), \mathrm{CoMoO}_{4}([]), \mathrm{NiMoO}_{4}(\mathrm{x})$.

Figure 4. SEM-EDX maps representing the dispersion of molybdenum (blue), magnesium (red), cobalt and nickel (green) of Co-Mo (a-d) and Ni-Mo (e-h) catalysts' selected regions (indicated in a and c) at a calcination temperature of $700^{\circ} \mathrm{C}$.

Figure 5: SEM $(a, b)$ and TEM $(c, d)$ micrographs of crystal structure obtained from catalysts Co-Mo (a,c), and Ni-Mo (b,d) at a calcination temperature of $800{ }^{\circ} \mathrm{C}$. Insets show Fast Fourier Transforms of the selected region of catalyst platelets.

Figure 6: SEM micrographs of MWCNT materials obtained with Co-Mo (a), Ni-Mo (b) catalysts. 
Figure 7: TEM micrographs of MWCNTs obtained from catalysts Co-Mo (a-c) and NiMo (d-f).

Figure 8. Raman spectra of MWCNT materials produced by Co-Mo and Ni-Mo catalysts calcinated at $700^{\circ} \mathrm{C}, 750^{\circ} \mathrm{C}$ and $800^{\circ} \mathrm{C}$.

Figure 9. XRD patterns of MWCNT materials produced by Co-Mo and Ni-Mo catalysts at a calcination temperature of $700^{\circ} \mathrm{C}$. Symbols: $\mathrm{Mo}_{2} \mathrm{C}\left({ }^{*}\right), \mathrm{MgO}\left({ }^{\wedge}\right), \operatorname{MWCNT}(\mathrm{o})$.

Figure 10: Proposed growth mechanism in 4 steps: 1) Reduction to form catalytic active metal clusters. 2) Stabilization and nucleation of metal carbides nanoparticles. 3) MWCNT growth. 4) Exfoliation of platelet-like catalyst structure. 